\title{
Imagen, virtualidad y heterotopía. Reflexiones acerca de la imagen y su función heterotópica ${ }^{1}$ \\ Image, virtuality and heterotopy. Reflections about the image and its heterotopic function
}

Recibido: 15 de octubre de 2015 - Revisado: 13 de mayo de 2016 - Aceptado: 23 de junio de 2016.

Juan Diego Parra Valencia ${ }^{2}$

\section{Resumen}

El presente artículo aborda la noción de imagen, como campo problemático, más allá del régimen semiológico instaurado desde los modelos lingüísticos. En general, la noción de imagen ha estado vinculada solo a la idea de "representación", desde la cual se logró domesticar su potencial instaurador de estados de sensibilidad. Consideramos pertinente ampliar campos de reflexión sobre aspectos que no se restrinjan a su funcionalidad representacional y para ello, nos apoyaremos en el concepto de heterotopía de Michel Foucault, el cual nos servirá de ayuda, por cuanto expande el campo de reflexión estética y permite integrar a la dimensión simbólica, la función virtualizante de la imagen como productora de estados de sensibilidad. La imagen, a nuestro entender, funciona como una heterotopía, es una tipología espacio-temporal no convencional, y por tanto es estructurante y configuradora de realidad, tanto en términos sensibles como inteligibles.

\section{Palabras clave}

Imagen, topos, espacio, heterotopía, Michel Foucault, Regis Debray, Gilbert Simondon.

\begin{abstract}
This article approaches the notion of image, as a problematic field, beyond the semiological regime established from the linguistic models. In general, the notion of image has been linked only to the idea of "representation", from which it was possible to domesticate its potential to establish states of sensitivity. We consider it relevant to expand reflection areas on aspects that are not restricted to its representational functionality and for this, we will rely on Michel Foucault's concept of heterotopy, which will help us, as it expands the field of aesthetic reflection and allows to integrate the symbolic dimension, the virtualizing function of the image as the producer of states of sensitivity. The image, in our opinion, functions as a heterotopy, it is a non-conventional spatio-temporal typology, and therefore it is structurer and configurator of reality, both in terms sensitive and intelligible.
\end{abstract}

\section{Keywords}

Image, tropes, space, heterotopy, Michel Foucault, Regis Debray, Gilbert Simondon.

\footnotetext{
1 Artículo resultado de investigación derivado del proyecto: "Transversalidades estéticas en la esfera semiótica. Elementos para un análisis semioestético de las artes". Facultad de Artes y Humanidades, Instituto Tecnológico Metropolitano, Medellín, Colombia.

${ }^{2} \mathrm{PhD}$. en Filosofía. Docente de la Facultad de Artes y Humanidades del Instituto Tecnológico Metropolitano, Medellín, Colombia. Correo electrónico: juanparra@itm.edu.co

Para citar este artículo use: Parra, J. (2017). Imagen, virtualidad y heterotopía. Reflexiones acerca de la imagen y su función heterotópica. Civilizar Ciencias Sociales y Humanas, 17(32), 229-244. Doi: $10.22518 / 16578953.828$
} 


\section{Introducción}

Desde su constitución como "objeto cultural", la imagen se ha ubicado en el centro mismo de nuestra relación con lo real. Su función no siempre ha sido "representativa", y por mucho tiempo, hizo parte de la realidad sensible como elemento considerado tan real como los objetos animados. De hecho, aún más poderosa que dichos objetos, la imagen refería y sustituía las fuerzas sobrenaturales. Muchos autores relacionan la aparición de la imagen con la consciencia humana de la muerte (Debray, 1994) y establecen puntos de intersección entre el arte y la religión. El fenómeno religioso, que nos permite concebir la trascendencia, es a la vez un configurador de estados de sensibilidad que podemos ver expresados de manera análoga en la experiencia sublime que provoca el arte (por lo menos en su acepción estética moderna y que debemos, formalmente, a Kant). Tanto la religión como el arte conciben una experiencia sensible más allá de las capacidades físicas del cuerpo y exigen competencias imaginativas. Dichas competencias, si bien pueden estar ligadas a la comprensión del mundo concreto y perceptible, llevan también a la exacerbación de dichas experiencias más allá de los momentos experienciales mismos, ya hacia el pasado como recuerdo, ya hacia el futuro como expectativa y mucho más como construcción de mundos paralelos que se habitan simultáneamente a los espacios de sensibilidad corporal. No es vana la relación etimológica entre imagen e imaginación. Mucho antes de que el hombre hablara de "pensamiento" ya había construido mundos imaginados, en y desde los cuales podía pensar por supuesto, pero cuyo objetivo no consistía precisamente en "pensar" o "hacer pensar".

Imaginar, que bien puede definirse como "vivir en imágenes", no es solo representarse la realidad, sino concebir experiencias más allá, más acá o en paralelo con la realidad perceptible. Si eso ha sido posible es porque la potencia del pensamiento es justo la capacidad de "sa- lirse de sí”, ir más allá de aquello que no solo puede experimentar el cuerpo, sino que puede concebir la mente. Mas, ese "salir" de sí, ese "no estar del todo "aquí", es precisamente una experiencia virtual, como lo veremos un poco más adelante. De esta manera, si pensar e imaginar están constituidos por la misma potencia humana de "no estar ahí" del todo, ambas acciones (que bien pueden ser una sola) definen la posibilidad humana (demasiado humana) de virtualizar. Y si virtualizar se define por la potencia (en sí misma, la virtud es fuerza, ímpetu) de salir(se), exteriorizar(se), tanto del "aquí" físico y geográfico como del "ahora" mental y temporal, entonces virtualizar implica desplazarse a otro "lugar", otro "topos". Y si ese "topos" se constituye en un campo posible (o concebible, aunque no necesariamente experimentable físicamente), no habría una facultad más propicia para entender dicha capacidad que la imaginación. En sí misma, la imagen como hábitat de la imaginación, o como producción del acto imaginativo, en el cual a su vez puede darse dicha imaginación, es la que define virtualmente el espacio (el "topos") del pensar mismo. Y dicho pensar, a su vez, cumple con una función explicativa de las experiencias, tanto las imaginadas como las vividas, hasta tal punto que pueden confundirse y configurar escenarios alternativos redundantes e incluso sustituyentes de la realidad sensible.

Es por ello por lo que nos interesa pensar la imagen como campo de problematización que define no solo la experiencia sensible, sino la posibilidad misma de asimilar dicha experiencia y de proyectar cambios y transformaciones, tanto al pasado como al futuro. La imagen, pues, no es solo representación de las percepciones, es también un espacio constitutivo de lo que comprendemos como realidad (y que influye en el autoreconocimiento), y es a partir de la imagen que conformamos un campo de acción que permite articular las experiencias sensibles con los esfuerzos inteligibles, por cuanto una imagen, aunque no es una entidad "existente" en sentido fáctico, evidentemente es más 
que una idea abstracta. No es del todo fáctica porque siempre parece referida a algo más que ella no es; pero es más que una idea porque su campo de acción abarca la concreción material en el espacio. Y es desde aquí que buscaremos reconocer el poder de la imagen como espacio alterno (o "espacio-otro"), imaginario, virtual, pero no menos real, de la realidad aceptada por el hábito, la cual configura procesos de transformación en constantes confrontaciones con las ideas sobre el tiempo y el espacio. La imagen, pues, es espacio, lugar, tanto de pensamiento como de percepción que localiza, deslocaliza, conforma, deforma y transforma nuestra idea de mundo.

La imagen es así un "espacio-otro", es decir, una heterotopía (como veremos, la define Michel Foucault). Y es esa "otredad" del espacio, lo que determina la topología perceptiva, nunca tan latente como en las relaciones actuales con los dispositivos tecnológicos, la expansión de la realidad-pantalla, que nos satura visualmente de imágenes que fungen y fingen realidad permanentemente. Estamos en la época de la sincronía perceptiva con los estímulos ópticos. Los mensajes visuales circulan de manera veloz al ritmo con el que pasa el tiempo de la experiencia vital y existe una obsesión con declarar la idea de "tiempo real" en cada proceso comunicacional. La conciencia atenta del proceso retencional cede su función al flujo de las imágenes que distribuyen paquetes de emoción y sensibilidad a domicilio ${ }^{1}$, mientras que el receptor cada vez más atrapado en el plano de realidad diferida, asume los mensajes como datos directos de la experiencia inmediata. A través de los dispositivos móviles de la hiperconectividad tenemos un depósito infinito de imágenes latentes, virtualizadas, ya no sujetas a superficies concretas, que forman mundos posibles y no incomposibles ${ }^{2}$ para nuestra capacidad cognitiva de retención consciente. Esta sincronía es inédita y propia de la época teletecnológica actual, pero vista con detenimiento, es una extensión global, masiva y poderosa de la atávica relación humana con la imagen. Podemos decir incluso que tal despliegue programático de información óptica, por parte de agencias de producción de lo simbólico, no hace "uso" de las imágenes para la difusión de mensajes, sino que son las imágenes las que permiten tal envergadura en el despliegue de difusión. La imagen tiene poder, ella misma es una potencia (virtual), y es por dicho poder que su participación siempre es activa en la conformación de lo real. Por ello es la imagen, por encima de la palabra o la escritura (que a su vez es también imagen gráfica del habla) la que ha determinado sistemas de control político y/o religioso desde las antiguas civilizaciones.

\section{Imagen, virtualidad y representación}

Una buena parte de los análisis sobre la imagen como campo problemático evaden la propia idea de "imagen" intercambiando su función desde los criterios de "representación". En general los estudios visuales plantean un reconocimiento estético de la imagen configurando las formas de recepción subjetiva y los procesos colectivos de adopción, pero no cuestionan la idea de "imagen" misma, que toman como condición a priori del análisis. Para los estudios visuales, la imagen es un tercero excluido, a partir del cual se piensa, pero sobre el cual no se problematiza. Esto provoca la impresión de que los valores de la imagen no tienen historicidad, por un lado, y por otro que el carácter hegemónico de la imagen actualmente sea una condición particular de nuestra era. Así el valor de complejidad de las imágenes teledifundidas en la actualidad parece representar un grado mayor con respecto a las imágenes transmitidas desde otras estrategias y logísticas en épocas anteriores, incrementando el nivel de cercanía y fidelidad con la realidad referenciada. Esto querría decir que la idea general de que la imagen es una representación de la realidad no solo no (se) cuestiona sino que ya no inquieta, convirtiéndose en premisa irrebatible. Es importante resaltar que la forma de adopción contemporánea de la imagen proviene de las estrategias de 
uso de los dispositivos digitales, a través de los cuales se fabricó la idea genérica de virtualidad desde la réplica directa de la percepción sensible humana, desdiciendo las aventuras de orden utópico y heterotópico de los primeros años de revolución virtual durante la década de los 80 . Nuestra intención es pues desviar la atención de este régimen representativo, nuevamente hacia la imagen como territorio "aún no pensado del todo".

La estrategia de asimilar "imagen" y "representación", cuya herencia podemos detectar en las pugnas platónico-aristotélicas contra la producción de simulacros, ha logrado neutralizar el poder efectivo de la imagen. Desde la idea de representación la imagen nunca antecede a la percepción sino que es una consecuencia de ella, por lo tanto, se le entiende como deriva de lo real que lo antecede. La imagen como representación aparece como doble referencial de la experiencia, que si bien la constata y reproduce no puede reemplazarla. Esta idea de imagen nos ubica en un escenario cómodo de análisis por cuanto se anula su poder productivo en cambio de uno reproductivo. Así, si bien el mundo de percepciones visuales da cuenta de la realidad, se le entiende como un mundo de "segunda mano" y es esta la idea que subyace en la animadversión generalizada, de herencia platónica, al simulacro y la falsedad de las imágenes, frente a un pretendido mundo "verdadero". Esta idea se ha mantenido casi impoluta, a pesar del desarrollo tecnológico de la digitalización, a partir del cual se configuró la idea genérica de "realidad virtual"3. Así pues, el "lugar" de las imágenes más generalizado, y casi canónico, su "topos", ha sido la representación y por tanto la funcionalidad de ellas configura un escenario restringido articulado de valores de analogía, semejanza, identidad y oposición. Dichos valores mantienen el campo hegemónico de análisis que pretende diferenciar lo real de lo simulado y por tanto establecen distinciones entre lo objetivo y lo subjetivo. Esta postura plantea un escenario indiscutible a nivel fáctico desde el cual se derivan formas representativas referenciales.
Es desde aquí que se entiende convencionalmente la figuración de carácter mimético (en el contexto del arte denominado "figurativo"), como una reproducción de la percepción. Pero esta postura generalmente obvia el carácter mismo de la imagen como productora de sentido: por ejemplo, la invención gráfica de la perspectiva renacentista definió una determinada forma de ver, que confluye con intereses cientificistas que dotan de racionalismo la imagen, determinando cambios estructurales a las ideas de semejanza - de gran carga animista- que hasta ese momento regían la percepción. De hecho, las revoluciones vanguardistas surgidas desde el Romanticismo buscaban, precisamente, superar el carácter de racionalidad fría que sostenía la representación científica, hasta el punto que activaron el problema mismo de la expresión, cardinal para la investigación estética actual.

De lo que hablamos es de que el sentido de lo representativo no necesariamente coincide con formas de estabilización perceptiva que reproduzcan la experiencia del mundo, sino todo lo contrario: la formalización de estados de sensibilidad son los que filtran el valor de lo realexperimentado. En eso ha consistido el arte, la ciencia y la filosofía, cada uno demarcado por materias primas distintas. Tanto los paradigmas científicos como los corpus conceptuales filosóficos, y la formalización estilística en las artes, propenden por la estructuración de campos del saber que resuenen en las experiencias sensibles. Y es allí donde encontramos la importancia del problema de la virtualización. Tal como la define Pierre Levy (1999) "la virtualización es uno de los principales vectores de la creación de realidad" que debe entenderse como vector de hominización (p. 20). Virtualizar es desterritorializar, desprenderse de las condiciones de percepción habitual para habitar campos indeterminados allende el propio cuerpo. Cuando hablamos del cielo, el mundo de las ideas o del espíritu, cuando vivimos en el contrato o en la ley, claramente habitamos mundos virtuales, mundos recreados, ficcionados, que establecen campos de integración afectiva y efectiva entre 
los cuerpos, sea en forma conceptual, teorética o estética. Lo virtual no se opone a lo real (consigna con la que ha tratado de definirse), sino a lo actual. Dice Levy (1999) que si bien lo real puede asemejarse a lo posible, "lo actual no se parece en nada a lo virtual: le responde" (p. 19). La relación virtual-actual no debe confundirse con la relación posible-real. Deleuze (1987) lo explica perfectamente:

Lo posible es lo que se realiza (o no se realiza); ahora bien, el proceso de realización está sometido a dos reglas esenciales, la de la semejanza y la de la limitación. La razón estriba en que se considera que lo real es a imagen de lo posible que realiza (sólo tiene de más la existencia o la realidad, lo cual se traduce diciendo que desde el punto de vista del concepto no hay diferencia entre lo posible y lo real) y como no todos los posibles se realizan, la realización implica una limitación por la que determinados posibles se consideran rechazados o impedidos, mientras otros "pasan" a lo real. Lo virtual, por el contrario, no tiene que realizarse sino actualizarse; y la actualización ya no tiene como reglas la semejanza y la limitación, sino la diferencia o la divergencia y la creación (pp. 101-102).

Aquello que entendemos por "realidad" es un condensado de experiencias virtuales que se actualizan de acuerdo con estructuras rigentes para la experiencia sensible colectiva. Si un campo de saber determina epistemológicamente, por ejemplo, que la tierra es plana, la relación de los individuos con sus experiencias estará determinada por ese saber. Dicho saber puede cambiar, por lo cual los campos epistémicos necesariamente modifican el sentido de lo percibido. Hoy en día, precisamente, aunque los datos intuitivos sobre el movimiento de la tierra nieguen la experiencia nos es imposible pensarla quieta. $\mathrm{Y}$ es precisamente porque nuestro campo de integración perceptiva está condicionado por la experiencia virtual de orden teórico. Y justo es eso lo que se ha dado en llamar una "imagen del mundo". Ninguna imagen del mundo puede existir si no es ya en sí misma virtual y virtualizante. Es por esto que Levy (1999) afir- ma que "lo virtual, a menudo, $<<$ no está ahí $>>$ " y Serres (1995) dice que lo virtual es lo "fuera de aquí". La imagen del mundo configura las percepciones, y no necesariamente "desde" las percepciones mismas. No en vano, tampoco, es que la palabra "imaginación" provenga de la "imagen". Si la imaginación es lo que nos libera de los límites perceptivos, entonces no hay imaginación sin virtualidad. $\mathrm{Y}$ es precisamente ese el sentido prístino de lo virtual en tanto potencia (y no solo posibilidad): es la fuerza latente -virtual viene de virtus: fuerza, potencia- que siempre está dispuesta a activarse y actualizarse. $\mathrm{Si}$ bien en nuestra contemporaneidad insistamos en la relación causal y consustancial entre virtualidad y tecnología, la experiencia de lo virtual es constitutiva del hombre y su sentido deriva en problemas de orden ontológico más que tecnológico. Mas, lo cierto es que precisamente, de acuerdo con los campos epistémicos virtuales, existen estrategias y logísticas de presentación (no solo de re-presentación) de lo real a través de dispositivos técnicos. La fabricación de imágenes miméticas, cargadas de semejanza con respecto al objeto representado, es una de estas estrategias, pero también lo es la representación diagramática, icónica y simbólica que usan la ciencia y la filosofía. Y todo ello lo hacen a través de imágenes.

La imagen, pues, si bien puede ser un dato para acceder a lo real, dicha realidad es también su propia construcción, la imagen es estructurante en sentido virtual. La imagen no se reduce a su función representativa, en términos figurativos, esta manera de verla siempre ha dependido de intereses por domeñar su poder de realidad. La imagen es un campo problemático, un sistema complejo ${ }^{4}$ que, si bien comprende un escenario elocuente de representación, no se restringe de manera unívoca a esta función. De aquí que para los propósitos argumentales relacionemos la idea de campo con la de "topos", es decir, lugar de articulación en el que confluyen diversos escenarios y perspectivas. Entender qué es una imagen no nos urge tanto como derivar de su idea una funcionalidad de 
implicaciones reales. La imagen será, a nuestro entender, un escenario (incluso en términos teatrales) de construcción de realidad, pero no es un escenario específicamente físico sino un estado virtual que puede ser comprendido, asimilado y aprehendido, de aplicabilidad directa en la realidad fáctica. Por ello, relacionaremos cuando llegue el momento, esta idea de imagen con la de heterotopía, que obtendremos de Michel Foucault. En términos escuetos por ahora, imagen y heterotopía podrán compartir significaciones y características, casi como si fueran el mismo espacio de integración sensible e intelectual. Dicha compartimentación entre imagen y heterotopía, sugiere una posibilidad analítica no restringida al análisis prescriptivo de la semiología, la iconología o algunas aproximaciones de los estudios visuales, que ya hemos mencionado. La imagen heterotópica, desde nuestra perspectiva, configura un campo virtual desde el que se actualizan experiencias sensibles, y donde confluyen el tiempo y el espacio.

\section{Imagen, espacio y memoria}

Es necesario precisar que la imagen, sea como espacio de integración sensible o como campo de activación intelectiva, requiere de soportes y dispositivos de difusión y transmisión. De acuerdo con dichos dispositivos se han establecido formas de adopción social de los mensajes que derivan en estructuras de pensamiento y epistemes de influencia histórica (imágenes de mundo). En este caso, la imagen es un campo o espacio (topos) integrado que recoge la memoria colectiva y puede transmitirla a través del tiempo. No es igual que una imagen sea difundida en piedras, papiros o pantallas, y según el soporte usado la imagen traslada tipos específicos de información, tanto en términos diacrónicos como sincrónicos. Para nuestro caso actual, es claro hoy que tanto el cine como la televisión (y las subsecuentes experiencias de la imagen transportadas en dispositivos móviles), obedecen a una sistemática planificación de carácter sociológico e ideológico en la transmisión de mensajes efectivos, que actúan directamente so- bre las funciones retencionales cognitivas de los receptores, sincronizando los mensajes con la percepción misma y el flujo de realidad sensible. A partir de dicha sincronización garantizan que la noción de lo real, por parte de los espectadores, confluya con la percepción de los mensajes, debidamente programados y planificados previamente. En este caso, el espacio de la imagen articula el tiempo de percepción, con lo cual el filtro de recepción es cada vez menos funcional. Con la imagen audiovisual el espacio y el tiempo se condensan y la imagen parece hacerse volátil, hasta integrarse en el flujo de la percepción. Este tema lo analiza perfectamente Bernard Stiegler (2004) en su trabajo sobre La técnica y el tiempo, consintiendo con que los dispositivos de difusión, en tanto objetos técnicos, si bien exteriorizan la memoria individual, aceleran los procesos retencionales hasta sincronizarlos con la percepción directa y reemplazan por completo el proceso de adopción consciente. En este caso, el desarrollo tecnológico parece privar a la imagen de sus funciones espaciales (pues se diluye en el flujo de la percepción) y temporales (pues al ser sincrónica, evade la retención). Para nuestros propósitos, consideramos que esta privación de sus capacidades es solo aparente, pues con el desarrollo amplio de la imagen audiovisual no solo no se "supera" sino que se insiste en la relación atávica con las imágenes. En cada uno de sus estados de realidad, adecuados a los tipos de soporte, la imagen siempre es anacrónica, genera una experiencia antigua vinculada con la producción de sentido en la realidad fáctica, a través de su potencia de virtualización. Por ello, la imagen es heterotópica, porque establece un vínculo de carácter sensible que activa la capacidad mnemónica.

Esta idea que devuelve potencia práctica a la imagen nos obliga a separarnos de fundamentos semiológicos que entienden la imagen como solo un dato comunicativo complejo, para acceder a escenarios de carácter estético, en sentido ampliado, que redunden en la identificación de la imagen como campo de integraciones sensibles, el cual garantiza exteriorizaciones fun- 
cionales y complejos simbólicos. En términos paleontológicos, podemos decir que la palabra y el cerebro son antecedidos por imágenes derivadas del movimiento y el gesto (Simondon, 2013) y también que los trazos, huellas y cortes sobre superficies no regulares anteceden, como imagen-memoria, a la escritura misma (Debray, 2001). De esto podemos deducir que la imagen comporta (es decir "trae consigo") un tipo de experiencia primordial del pasado que se actualiza permanentemente. La imagen habita una "infancia" del mundo (recordemos que infans es lo que "no habla"), una experiencia constituida por la insuficiencia e irrelevancia de la palabra, que mantiene latente, es decir, como virtualidad, la experiencia de la realidad, activando sensaciones atávicas. La imagen así, constituye lo real como experiencia, generando un espacio (alterno o paralelo) de indiscernibilidad entre las percepciones y las intelecciones, al tiempo que integra funcionalmente las formas abstractas con las experiencias sensibles. La imagen es más que una representación, ella misma configura un escenario de sensibilidad, un campo estésico que libera de la percepción directa del cuerpo y expande las funciones sensorio-motrices a espacios virtuales. Dichos espacios son los que configuran los denominados "espacios-otros" (o heterotopías) según los define Foucault, como veremos pronto. La imagen pues está atada al campo de sensibilidad, es decir "el espacio", la forma exterior de percepción, y es por ella que el carácter mismo del tiempo puede transformarse en memoria activa exteriorizada del recuerdo individual. Así, más que una representación de la realidad, la imagen es configuradora de realidad, ella constituye no solo la aparición de un mundo-otro paralelo y referencial de las percepciones, sino que es propulsora de las capacidades abstractivas humanas: su función es productiva y no (solo) reproductiva. Es, por supuesto y por tanto, algo no reductible al régimen de la representación.

Así, la imagen no proviene de la capacidad racional de abstracción perceptiva, sino que está en el origen mismo de la cognición.
Dice Régis Debray (1994) que el trazo como marca específica es una verdadera revelación paleontológica, pues si bien de muchos animales se puede decir que tienen una "lengua" y se comunican, e incluso que los primates se sirven de herramientas, ninguno practica incisiones y entalladuras como el Homo sapiens (pp. 100101). El pictograma y el jeroglífico, tal como los llamamos hoy, desde la esfera semiótica, son imágenes que restituyen el carácter funcional activo de una experiencia que evidentemente no era representacional. Fueron las imágenes, sean éstas trazos, cortes, entalladuras, incisiones, glifos, heridas, cicatrices, las que permitieron el salto a ese "otro-mundo" abstracto, de carácter virtual y heterotópico, en el que se podían hacer cálculos, medidas y pronósticos. Nada de representación sino formas concretas y funcionales de intervención sobre el espacio que permitían comprender el tiempo. Las imágenes surgieron al mismo tiempo en que se fabricaba la idea de "espacio" como entidad pensable. Estas imágenes, además, eran funcionales, servían como campos de integración del acto y el pensamiento, produciendo sentido y expandiendo los escenarios de comprensión más allá de lo funcional y práctico. Nuestra relación con la imagen, por ello mismo, no se restringe a las complejidades de codificación semiológica que entiende por ella (la imagen) mensajes provenientes de una volición comunicativa. Nuestra relación con la imagen es constitutiva de nuestra condición ontológica, es la restitución del ser al que nos dirigimos (como diría Heidegger, 19945), pues es precisamente la infancia del mundo, es decir, el tiempo sin tiempo en el que aún no teníamos tiempo. No debe asombrarnos la frase perturbadora de Picasso al ver las pinturas de Altamira: "después de Altamira todo es decadencia", decía, y mucho menos la idea de Breton al pretender que el espíritu contemporáneo debería propender porque "el ojo exista en estado salvaje". No puede ser más elocuente para demostrarlo que las revoluciones de la vanguardia artística contemporánea siempre hayan buscado el futuro en lo primitivo: Picasso, Kandinski, Cezanne, 
Klee... La imagen proviene de un tiempo en el que aún no se habla, en el que aún el logos no se configuraba. Por eso activa un campo inconsciente inasignable a la memoria y por eso es partir de ella, de la imagen, que la memoria se constituye. De aquí que como lo evidencia Debray (1994), "el nacimiento de la imagen está unido desde el principio a la muerte" (p. 19). La imagen no es un código, o por lo menos su función no es ser código comunicativo; aunque evidentemente comunica, la imagen comporta un valor ontológico que nos introduce en aquello que denominamos "mundo" y de ahí su potencia expresiva que anula la diégesis desde el mutismo absoluto y soberano. Es claro que de las imágenes se puede hablar, pero ellas mismas no hablan, aunque parezca que lo hicieran, gracias a los artilugios técnicos (que nos llevan desde los autómatas hasta las imágenes audiovisuales y los hologramas de las teletecnologías digitales). Una imagen, al no ser diegética, no tiene traducción, por lo tanto, no activa las mismas funciones cognitivas que la lectura y la palabra. $\mathrm{Y}$ vamos más lejos, la propia escritura no es derivada del habla sino de la imagen que se apropia de manera directa de las modulaciones fonéticas y las inscribe en superficies con forma de código. Y es por esto que Derrida (1978) habla de una "archiescritura" como función de origen primordial (ficticio, por supuesto) de la escritura que no puede ser derivada del habla o representación de ella, sino una concreción de diferenciales que marcan (trazan o inciden) el origen retroactivo del ser en el espacio.

Al inscribirse en el espacio, la imagen presenta el tiempo, porque ella misma determina un campo sensible de concentración que deriva en memoria exterior. La marca, tanto en sentido indexical como simbólico, establece un cruce entre el presente activo y el recuerdo latente. Así funcionan la sepultura y la lápida, por ejemplo: son evidencia de la presencia ausente. Dicha presencia ausente configura la posibilidad de abstracción y también la consciencia del campo de activación de los recuerdos. Por ello los tótems y las esculturas establecen vínculos con seres rigentes del bienestar comunitario. A la vez, la imagen que acompaña como gesto la experiencia comunicativa, es el trazo móvil que define el dato comunicado, y por ello las técnicas de recuerdo, es decir, las mnemotecnias, configuran escenarios de enseñanza (es decir, de transmisión simbólica) a partir de dispositivos externos sobre los que recae el recuerdo colectivo. La imagen es memoria porque recoge el tiempo en el espacio que ella misma es.

\section{La imagen y el concepto de heterotopía}

Llegados a este punto consideramos pertinente dar una definición de imagen. No escarbaremos mucho en la etimología del imago, aunque consideramos pertinente mencionar que su acepción como "representación" llana ha determinado el régimen semántico con el que se ha popularizado la palabra "imagen". La idea del imago proviene de la figura especular, que puede tener que ver con experiencias fantasmáticas de carácter psíquico o bien reflejos producidos por espejos o vidrios. La elaboración de figuras referidas a objetos de la realidad, por tanto, fueron llamadas imagos y desde allí, por relación semántica con la idea griega de "phantasma", tenemos una idea general de la imagen como simulacro. Para nuestro objetivo, vemos más pertinente ahondar en la brillante definición que dio Henri Bergson (2006) en su texto Materia y memoria, que coincide con la idea más primitiva de imago, pero a partir de un interés definido sobre las características funcionales de la percepción. En Bergson, imagen y percepción redundan en la apropiación de la realidad, tanto a nivel físico como mental. Dice que todo lo que percibimos es imagen y la define como "una cierta existencia que es más de lo que el idealismo llama representación, pero menos que lo que el realismo llama una cosa, una existencia situada a medio camino entre la $<<\operatorname{cosa}>>$ y la $<<$ representación $>>$ " (pp. 25-26). La imagen es como una membrana que articula lo sensible y lo inteligible y en la cual se resuelve nuestra apreciación del mundo. La imagen es una suer- 
te de "espacio-frontera" que dinamiza las relaciones entre el pasado-recuerdo y el presenteacto, por lo cual es un espacio temporalizado o un tiempo espacializado. La imagen es menos material que la "cosa" y más concreta que la "idea", por tanto no es del todo una experiencia sensible pero sí más que una abstracción cognitiva. Es un espacio-otro a medio camino entre la materia y la idea, no está del todo ni en el teatro de lo inteligible ni en la experiencia de lo perceptible. Es lo que, con Foucault (1984a), podríamos denominar una heterotopía, es decir, un espacio-otro, un emplazamiento de alteridad que determina la exterioridad como anverso y reverso de las prácticas cotidianas.

Para poder identificar la idea de imagen con la de heterotopía, es necesario describir cómo Foucault define esta última, conceptualmente, a partir de la descripción de sus atributos o propiedades. Foucault señala que las heterotopías indican, por contigüidad, los campos de interacción común desde la distancia crítica. Dice que se rigen por seis características que determinan el valor de proximidad existencial con lo normativolegalizado en la que se comparten atributos, por participación óntica. Veámoslas con detalle:

1. La primera característica tiene que ver con la relación entre crisis, desviación y normalidad. Hay heterotopías que sirven, en tanto alteridad espacial, para los pasos (rituales o no) de semiestados psico-biológicos a constituciones orgánicas e institucionales (espacios de preparación disciplinaria y pedagógica, por ejemplo, o momentos no temporalizados que, según la adecuación provisional de un lugar, garantizan los pasos de la pubertad a la adultez, o de la virginidad a la sexualidad). Dentro de esta característica están también los lugares de desviación que funcionan como intervalos temporales espacializados donde se corrigen los comportamientos de infractores, durante un tiempo medido según los grados de anormalidad (cárceles, manicomios, hospitales y geriátricos).

2. La segunda característica de las heterotopías tiene que ver con la condición analógica de dimensiones referenciales que permite reconocer una suerte de duplicación espacial concreta, pero que está referida a un lugar-otro no asignable. Un ejemplo claro de esta heterotopía es el cementerio donde reposa la materialidad de entidades espiritualizadas, que solo pueden ser referidas. Por lo tanto, su funcionamiento determina la constatación de una presencia ausente que se refiere a un lugar moratorio adicional no visible, pero al cual ha de accederse gracias a la morada efectiva donde se refiere la ausencia. La entidad matérica presente participa, por contigüidad, de las cualidades ontológicas de la ausencia referida.

3. La tercera característica implica la superposición de capas del tiempo integradas en un dispositivo espacial de manera contradictoria. Esto ocurre en espacios de articulación simbólica en los que, a partir de estrategias de transmisión, se crea una temporalidad alterna donde se desarrollan acciones no sincrónicas con la temporalidad de expectación. Esto es lo que ocurre en sesiones de escena teatral o en las pantallas de cine. Esta heterotopía implica también expansiones temporales en dispositivos cerrados, como el libro, que distiende el tiempo espacializado a través del lenguaje para dilatar los tiempos narrativos no equivalentes a los tiempos de lectura.

4. La cuarta característica heterotópica, muy cercana a la tercera, según Foucault, puede comprenderse como heterocronía por cuanto implica escenarios de organización temporizada donde se da orden espacial a simultáneos que deberían regirse por orden 
de sucesión, por lo tanto, se crea un dispositivo de superposición temporal de superficie. Esto ocurre claramente en las bibliotecas y los museos (también en los cementerios, aunque estos no están determinados por órdenes de simultaneidad claros). Estos espacios-otros son dispositivos de transmisión como el teatro y el cine, pero su función no se orienta por el desarrollo temporal alternativo, sino por la alteración secuencial a partir de la espacialización de simultáneos. En esta heterotopía se acumula el tiempo de manera intensiva de acuerdo con la organización espacial, como ocurre en las fiestas y carnavales, donde se habita un espacio temporalizado según cálculos de caducidad. El tiempo acumulado que se consume de manera intensiva permite habitar la contracara de la experiencia cotidiana hasta fabricar un ser-otro ficticio y solo visible durante el festejo, de aquí que esta dimensión heterotópica tenga que ver con la anterior (el teatro, el cine, el libro) donde el espacio yuxtapone diversos mundos posibles no incomposibles.

5. La quinta característica heterotópica implica la condición de clandestinidad minoritaria con respecto a escenarios hegemónicos que generalmente se resuelven en pactos secretos que exigen compromisos férreos de fidelidad. Las sociedades secretas y los guetos son claramente oficiantes de esta característica heterotópica.

6. La sexta cualidad de la heterotopía, del mismo linaje que la anterior, está determinada no por el acceso al espacio clandestino secreto, sino por la conformación de escenarios de hábitat permanente en los cuales se desarrolla un tipo de vida autoregulada que no cuenta con la exterioridad, como una suerte de isla oceánica que regula su deriva según ritmos afianzadores de conducta.
No en vano Foucault dice que el mejor ejemplo de esta heterotopía es el navío que se hace a la mar como un lugar sin lugar. El problema de esta idea de espacio-otro no es el espacio como tal sino sus habitantes: ¿cómo es el navegante, el corsario, el náufrago? He ahí el valor de esta heterotopía.

Bien, hecha esta necesaria relación de características heterotópicas según el planteamiento de Foucault, debemos recapitular los elementos principales para poder integrarlos al análisis sobre la imagen que hemos hecho hasta aquí. Nos interesa, más allá de los ejemplos foucaultianos sobre tipos de heterotopía, entender los componentes del concepto que determinan como estertor la condición espacial localizada formalmente en los casos mencionados por el pensador francés. Lo que se quiere decir es que, si bien Foucault denomina como heterotopías algunos lugares específicos identificables en un análisis de carácter cultural, lo que importa en dichos lugares no es su condición matérica o su denominación, sino su funcionalidad, y esta se desprende de las condiciones operativas del espacio que integra dinámicas de interacción colectiva. Es decir, lo heterotópico se define de acuerdo con los tipos de integración y composición que permite, dentro de un campo de reflexión. Es por esto que requerimos de la clasificación de cualidades heterotópicas conforme las describe Foucault más allá de los casos arquitectónicos ejemplarizantes que él propone y con ello podremos referir las características de la imagen según ciertas propiedades, más allá del criterio de "representación". Las heterotopías, pues, cuentan con las siguientes cualidades:

1. Son espacios-frontera, no están al margen de algo, sino que son el-margen, son espacios de transformación y cambio, incluso de mutación;

2. Pueden cerrarse sobre sí mismas a partir de normativas autoorganizadoras; 
3. En ellas se activan campos vibracionales que resuenan dinámicamente en capas diferenciadas del tiempo, con lo cual permiten la contigüidad existencial con fenómenos distantes, tanto en el tiempo como en el espacio. Dichos fenómenos pueden ser organizados o no, de acuerdo la simultaneidad espacial y funcionan, además, como intervalos de intensidad que dilatan o contraen el tiempo de experiencia.

Estas cualidades, si bien Foucault las ejemplifica con claras intenciones didácticas, hablan de una tipología de espacio no convencional que de manera aleatoria adquiere nombres característicos. La heterotopía es una condición ínsita del espacio como devenir sensible y no un escenario a priori de la experiencia, donde se operan dinámicas de conformación diversa, configurando tipos variables de individuación.

El espacio-otro o heterotopía indica la condición no-estable de la experiencia espacial, el grado diferencial en el que el tiempo puede ser susceptible a retardo o aceleración funcional. La heterotopía, o espacio-otro no es lo otro del espacio, sino lo otro en-el-espacio que comporta (insistimos en el significado de comportamiento: "traer consigo") la idea misma de espacio porque se ubica no al margen sino en-el-margen. La heterotopía es el espacio de indiscernibilidad que configura la frontera y el límite, separando lo distinto, pero que no está en un punto diferenciado, pues es la diferencia misma. Desde aquí, la imagen como espacio heterotópico nos permite articular la idea propuesta por Bergson, quien la entiende como estado liminar superior a una representación, pero inferior a una cosa, que nos acercaría al carácter semiótico propuesto por Peirce, en el que signo es activo y funcional y no solo representacional ${ }^{6}$. Desde Bergson podemos entender, entonces, la imagen como un "topos" particular, un espacio-otro o heterotopía, que contiene una forma perceptible (de relación física y concreta) y a la vez una inteligible (de relación mental y abstracta), dando la posibilidad de una percepción temporal del espacio y configurando una relación espacial con el tiempo contraído. La imagen, pues, es una expansión del tiempo y una contracción del espacio. Es decir, la imagen no nace en un lugar sino que "da lugar", ella es "lo que falta al lugar", pues está "en lugar del lugar" y por ello mismo lo indica. Es entidad diferida que constata la entidad referida, pero que aparece como su representación, por lo cual nos obliga a experimentar la separación originaria de la percepción con respecto a lo real. Nos hace constatar nuestra separación del origen, porque ella está en su lugar (siempre en pasado) pero para indicarnos hacia donde ir (futuro). En este sentido, la imagen es aquello que espacializa una percepción y a la vez temporaliza una emoción, y esto aplica tanto para la imagen fija del cuadro o la fotografía, como para las imágenes móviles y fugaces de los dispositivos tecnológicos actuales. No se ubica en un espacio predeterminado, sino que "espacia": ella se ubica en el lugar del "lugar", del "topos", pero siendo un espacio-otro. Por ende, la imagen marca, señala, determina relaciones. De aquí que insistamos en otorgarle una dimensión heterotópica. Su condición puede reflejar lo real, mostrar lo real donde no está, tal como describe Foucault (1984a) la experiencia heterotópica del espejo, en el sentido primario del imago, que mencionábamos antes:

[...] es un espacio irreal que se abre virtualmente detrás de la superficie, estoy allá, allá donde no estoy, especie de sombra que me devuelve mi propia visibilidad, que me permite mirarme allá donde estoy ausente [...]; a partir del espejo me descubro ausente en el lugar en que estoy, puesto que me veo allá. [...] El espejo funciona como una heterotopía en el sentido de que convierte este lugar que ocupo, en el momento en que me miro en el vidrio, en absolutamente real, enlazado con todo el espacio que lo rodea, y a la vez en absolutamente irreal, ya que está obligado, para ser percibido, a pasar este punto virtual que está allá (p. 3). 
Foucault describe perfectamente la experiencia de lo virtual y a la vez configura un estadio de percepción desde la idea especular de la imagen a través del espejo, tal como el carácter etimológico nos revela el significado ancestral del imago.

Así, las características heterotópicas de la imagen determinan un tipo de percepción especial, que no debe reducirse a una elaboración mental que pueda o no materializarse, la imagen es el punto de integración de lo sensible con lo inteligible, está ( $\sin$ serlo) en el acto mismo de percepción y por eso es heterotópica: la imagen es un intervalo de percepción espacial que desfasa lo real del tiempo, es el campo de instalación entre la acción y la reacción. Es subjetiva y objetiva a la vez, y como lo define claramente Simondon, (2013) en el mejor sentido bergsoniano,

[...] se podría suponer que este carácter a la vez objetivo y subjetivo de las imágenes traduce de hecho este estatus de cuasi-organismo que posee la imagen, habitando el sujeto y desarrollándose en él con una relativa independencia por relación a la actividad unificada y consciente (p. 15).

Esta condición de cuasi-organismo es la que permite la deriva mimética traducible en la percepción del arte plástico y la sobredimensión de las experiencias esotéricas vinculadas con la magia que, por otro lado, perviven en el flujo cinemático de las imágenes que aluden al "tiempo real" (como es claro en la experiencia de percepción televisiva, expandida en los dispositivos móviles) que garantizan la sincronía sin distancia crítica (es decir, sin "espacio" de reflexión) de los flujos de conciencia, yuxtaponiendo estados de sensibilidad. El propio Simondon (2013) dice que "la imagen es el sustituto de la sensación, instrumento de actividad mental más manejable que la sensación misma” (p. 22). Es desde aquí que defendemos la constitución primordial de nuestro vínculo con las imágenes que hace que la experiencia contemporánea en la denominada "era de lo visual" solo sea una modulación de la permanente relación del homo con el imago. La imagen habita una posterioridad anterior de nuestra relación con lo real, nuestra relación con ella es totalmente anacrónica, ella no es una representación sino una condición de necesidad para nuestro habitar en el mundo, por cuanto es un depósito de sensaciones virtuales asignables a mundos relativos de la experiencia y de allí su poder hegemónico frente a los códigos verbales comunicativos.

En este caso, la imagen se ubica en un tiempo sin tiempo, es una virtualidad que se actualiza, un nudo de tendencias emocionales que no se reducen a la actividad mental de la imaginación o el entendimiento. Simondon (2013) insiste en que

[...] el pensamiento abstracto es sobre todo un freno, un medio de rechazo: calcula y muestra los inconvenientes, las consecuencias lejanas; las percepciones provocan un arrastre por la situación; sólo la imagen es de hecho reguladora, puesto que es bastante abstracta para liberar al sujeto de las situaciones apremiantes y bastante concreta para suministrar una muestra con posibilidad de ser fiel (p. 17).

Laimagenno es pues(solo)representación. Ella es un tipo de espacialidad temporalizada o temporalidad espacializada, es a la vez una heterotopía y una heterocronía, un espacio-otro y otro-en-el-tiempo, es un emplazamiento que define lo que falta (o no-es-del-todo) a partir de lo que sobra (o no-es-todavía).

Llegados a este punto debemos entonces recapitular los componentes de las heterotopías, rescatados de la exposición foucaultiana, para describir el estatuto de la imagen como espacio heterotópico:

1. Tal como la heterotopía, la imagen es una espacio-frontera, no está al margen de algo sino que es el-margen, es espacio de transformación y cambio, incluso de mutación: la experiencia 
del espejo es ejemplar para entender esta condición, pues desde ella se reconoce al ser en lo que no-es, y el espacio del reflejo es indicador del espacio reflejado, la imagen es un espacio-intervalo donde el ser sabe que no es lo que ve, pero que debe ajustarlo a lo que ve. La imagen determina el portal de reconocimiento del devenir que devuelve la idea según un desfase de adopción perceptiva.

2. Tal como la heterotopía, la imagen puede cerrarse sobre sí misma a partir de normativas autoorganizadoras: precisamente el carácter de constitución de la imagen permite un proceso de ralentización de las ideas obtenidas de la percepción que derivan en sistemas de autoorganización, con lo que se marcan límites de representación de tendencia paradigmática. Es en este punto que aparecen las ideas cerradas en sí mismas, tanto a nivel individual como colectivo y se sobredimensionan las condiciones identitarias de acuerdo con hábitos, conductas y conceptos. La imagen de autoorganización regulada es la que permite estabilizar la idea del sí mismo por encima del devenir de sí, es la que ofrece la opción del arquetipo, de la identidad y del paradigma, y es la que permitiría una "imagen del mundo" o una "imagen del pensamiento".

3. La imagen, además y como el espacio heterotópico, activa campos vibracionales que resuenan dinámicamente en capas diferenciadas del tiempo, lo que permite la experiencia de contigüidad existencial con fenómenos distantes, tanto en el tiempo como en el espacio (que pueden ser organizados o no), de acuerdo la simultaneidad espacial. Es precisamente esta cualidad de la imagen la que comporta el valor sim- bólico de la imagen como dispositivo de transmisión y de allí proviene su elocuencia comunicativa que la hace vigente a través del tiempo, independientemente de las modulaciones perceptivas y los campos de perspectiva conceptual. La imagen es un mensaje diacrónico que logra sincronía perceptiva con el observador, por lo cual integra datos de percepción variables entre tiempos, como cuando vemos una obra de arte que ha sido vista durante varios siglos por antiguos hombres: esta imagen es un palimpsesto de percepciones, de puntos de vista, un condensado de realidad sensible que superpone estratos perceptivos, que funcionan, además, como intervalos de intensidad que dilatan o contraen el tiempo de experiencia. La imagen, en tanto heterotopía, es un depositorio de realidad sensible que puede ser, como en la actualidad massmediática, distribuida a domicilio a través de dispositivos móviles.

Así, pues, si nuestra época es la de las imágenes y nuestros recursos ópticos se multiplican al infinito, hemos decir que la razón de ello es que no ha habido una época más heterotópica que esta, en la que nuestra exteriorización funcional implica emplazamientos cada vez más virtuales según experiencias sincrónicas en el flujo de imágenes que reemplazan, cada vez más, la conciencia atenta. Si nuestra era es la de las imágenes es porque ahora vivimos no ya la elucubración utópica que inyecta los deseos, sino en el campo vibracional intensivo de la contigüidad existencial con nosotros mismos, vivimos en la heterotopía. Y la posibilidad de vivirla la dan las imágenes aparentemente nuevas, pero de poder ancestral. Nuestra relación con la imagen es tan arcaica como nuestra relación con el espacio y el tiempo, y es por ello que ante la imagen regresamos a estados constitutivos del proceso cognitivo, en la imagen y por la imagen somos emplazados y 
desplazados, heterotópicamente, a la profunda raíz de nuestra estesia y cognición.

\section{Notas}

1 La expresión audaz de "distribución de sensibilidad a domicilio" la tomamos del ensayo "La conquista de la ubicuidad" de Paul Valéry (1928, citado en Valéry, 1999, pp. 131134), quien analizaba el creciente fenómeno tecnológico de la radio, como un sistema de articulación emocional que lograba sincronizar las consciencias y la atención a nivel global.

${ }^{2}$ A diferencia de la opción propuesta por Leibniz sobre los mundos posibles, la emergencia de las "realidades virtuales", permite que las experiencias sensibles habiten los mismos estados de percepción (es decir, los mismos mundos), para el consumidor de datos de sensibilidad: imágenes y sonidos se despliegan en paralelo e invaden por todos los flancos su disposición de atención consciente.

${ }^{3}$ La idea de "realidad virtual" es muy reciente. Se le atribuye a Jaron Lanier, creador en los años 90 de las primeras gafas de estímulos visuales que permitían la experiencia activa del mundo a través de imágenes hiperreales. Dichas gafas fueron denominadas de "realidad virtual" y definieron desde entonces la estrecha relación entre las tecnologías digitales y la conceptualización de lo virtual. En el contexto que lo usa Lanier, reemplaza la idea inmediatamente anterior de "realidad artificial", integrada en el imaginario de ciencia ficción proveniente de la literatura, precisamente creadora del término Ciberespacio (Ver: Neuromancer de W. Gibson (1984/2007)).

${ }^{4}$ Tal como lo expone de manera elocuente Joseph María Catalá (2005).

5 Precisamente Heidegger en su ensayo "Habitar, construir, pensar" recorre el sentido etimológico del ser a través de las ideas del construir y el habitar, conformando un escenario del pensamiento en el que es el espacio (habitado y construido, es decir, cuidado y edificado) el que permite la emergencia del ser. Así el espacio, como aperturidad, da cuenta de lo que se es, con lo cual el espacio no es un a priori funcional, sino un acto determinante y debe entenderse desde dimensiones ontológicas. Si la imagen es espacio, entonces, ella misma es constitutiva del reconocimiento de lo que somos y no su representación.

${ }^{6}$ Solo de manera referencial debemos decir que una diferencia fundamental entre la aproximación semiótica de Peirce (1988) y la semiológica de Saussure (1945), radica en que para el segundo el signo, si bien es convencional, da cuenta de una realidad con sentido, mientras para el primero, el signo "activa" la producción misma del sentido.

\section{Referencias}

Adorno, T. W., \& Horckheimer, M. (1997). Dialéctica de la ilustración. Fragmentos filosóficos. Madrid: Trotta.

Alonso, A. (2002). La nueva ciudad de Dios: un juego cibercultural sobre el tecnohermetismo. Madrid: Ediciones Siruela.

Ascott, R. (2003). Telematic Embrace: Visionary Theories of Art, Technology, and Consciousness. Berkeley: University of California Press.

Barthes, R. (1970). "Retórica de la imagen". En E. Verón, (Dir.), La semiología. Communicaciones $\mathrm{N}^{\circ} 4 \quad$ (pp. 127140). Buenos Aires: Editorial Tiempo Contemporáneo.

Bergson, H. (2006). Materia y memoria. Buenos Aires: Cactus.

Bordieu, P. (1997). Sobrelatelevisión. Barcelona: Anagrama. 
Brea, J. L. (Ed.) (2005). Estudios visuales: la epistemología de la visualidad en la era de la globalización. Madrid: Akal.

Casanueva, M., \& Bolaños, B. (Coords.) (2009). El giro pictórico: epistemología de la imagen. Barcelona: Anthropos.

Catalá, J. M. (2005). La imagen compleja. Barcelona: Universidad Autónoma de Barcelona.

Catalá, J. M. (2010). La imagen-interfaz. Bilbao: Servicio Editorial del País Vasco.

Crary, J. (2008). Las técnicas del observador: vision $y$ modernidad en el siglo XIX. Murcia: Cendeac.

Debord, G. (2007). La sociedad del espectáculo. Valencia: Pre-textos.

Debray, R. (1994). Vida y muerte de la imagen: historia de la mirada en occidente. Barcelona: Paidós.

Debray, R. (2001). Introducción a la mediología. Barcelona: Paidós.

Deleuze, G. (1987). El bergsonismo. Madrid: Cátedra.

Derrida, J. (1978). De la gramatología. México: Siglo XXI.

Derrida, J. (1998). Ecografias de la televisión. Entrevista con Bernard Stiegler. Buenos aires: Universidad de Buenos Aires.

Dery, M. (1998). Velocidad de escape: la cibercultura en el final del siglo. Madrid: Ediciones Siruela.

Duque, F. (2006). Esculpir el lugar. En A. Andrés Ortiz-Oses \& P. Lanceros (Eds.), La Interpretación del mundo: cuestiones para el tercer milenio (pp. 95-112). Barcelona: Anthropos.

Foucault, M. (1971). Las palabras y las cosas. México: Siglo XXI.

Foucault, M. (1984a). De los espacios otros. $A r$ chitecture Mouvement. Continuité, 5. Recuperado de http://yoochel.org/wp-content/ uploads/2011/03/foucalt_de-los-espacios-otros.pdf

Foucault, M. (1984b). Topologías (dos conferencias radiofónicas). Architecture Mouvement. Continuité, 5. Recuperado de hqttp://hipermedula.org/wp-content/ uploads/2013/09/michel_foucault_heterotopias_y_cuerpo_utopico.pdf Consultado en $01 / 07 / 2014$

Gibson, W. (2007). Neuromante. Barcelona: Minotauro.

Gubern, R. (1996). Del bisonte a la realidad virtual: la escena y el laberinto. Barcelona: Editorial Anagrama.

Heidegger, M. (1994). Construir, habitar y pensar (Trad. E. Barjau). Barcelona: Serbal. Recuperado de https://catedrasabugo.files.wordpress.com/2017/05/martinheidegger-construirhabitarpensar.pdf

Heidegger, M. (2005). ¿Qué significa pensar?. Madrid: Trotta

Kant, E. (1984). Crítica del juicio. Madrid: Espasa.

Levy, P. (1999). Qué es lo virtual?. Barcelona: Paidós.

Lotman, I. M. (1996). La semiosfera I. Madrid: Cátedra

Lovink, G (2004). Fibra oscura: rastreando la cultura crítica de internet. Madrid: Alianza. 
Martínez, S. (2010). La crítica de la cultura después de la cultura. Revista de Estudios Visuales, 7, 102-113. Recuperado de http://www.estudiosvisuales.net/ revista/pdf/num7/07_sergiomluna.pdf

Marx, K. (1976). El capital. Madrid: EDAF.

Merleau-Ponty, M. (1985). Fenomenología de la percepción. Barcelona: Planeta De Agostini.

Pardo, J. L. (1992). Las formas de la exterioridad. Valencia: Pre-textos.

Parra, J. D. (2014). Linajes técnicos, tradiciones culturales. Breve excursión por las transversalidades entre técnica y cultura. Trilogía. Ciencia, Tecnología y Sociedad, 6(11), 49-59.

Peirce, C. S. (1988). El hombre, un signo. Barcelona: Crítica.
Quéau, P. (1995). Lo virtual: virtudes y vértigos. Barcelona: Paidós.

Ranciere, J. (2009). El destino de las imágenes. Buenos Aires: Prometeo Libros.

Saussure, F. (1945). Curso de Lingüistica general. Buenos Aires: Losada.

Serres, M. (1995). Atlas. Madrid: Cátedra.

Simondon, G. (2013). Imaginación e invención. Buenos Aires: Cactus.

Stiegler, B. (2004). La técnica y el tiempo. El tiempo del cine y la cuestión del malestar (Vol. 3). Hondarribia: Hiru.

Stiegler, B. (2013). Economía de lo hipermaterial y psicopoder (Trad. L. A. Palau). París: Mille et une nuits.

Valéry, P. (1999). Piezas sobre arte. Madrid: Visor. 